\title{
BMJ Open Characteristics of patients included and enrolled in studies on the prognostic value of serum biomarkers for prediction of postconcussion symptoms following a mild traumatic brain injury: a systematic review
}

Eric Mercier, ${ }^{1,2,3,4}$ Pier-Alexandre Tardif, ${ }^{1}$ Marcel Emond, ${ }^{2,5}$ Marie-Christine Ouellet, ${ }^{6}$ Élaine de Guise, ${ }^{7,8}$ Biswadev Mitra, ${ }^{3,4,9}$ Peter Cameron,, ${ }^{3,4,9}$ Natalie Le Sage ${ }^{1,2}$

To cite: Mercier E, Tardif P-A, Emond $\mathrm{M}$, et al. Characteristics of patients included and enrolled in studies on the prognostic value of serum biomarkers for prediction of postconcussion symptoms following a mild traumatic brain injury: a systematic review. BMJ Open 2017;7:e017848. doi:10.1136/ bmjopen-2017-017848

- Prepublication history and additional material for this paper are available online. To view please visit the journal (http:// dx.doi.org/10.1136/bmjopen2017-017848).

Received 23 May 2017 Revised 21 July 2017 Accepted 2 August 2017

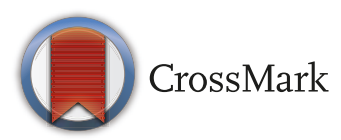

For numbered affiliations see end of article.

Correspondence to

Dr Eric Mercier;

eric.mercier.2@ulaval.ca

\section{ABSTRACT}

Objective Mild traumatic brain injury (mTBI) has been insufficiently researched, and its definition remains elusive. Investigators are confronted by heterogeneity in patients, mechanism of injury and outcomes. Findings are thus often limited in generalisability and clinical application. Serum protein biomarkers are increasingly assessed to enhance prognostication of outcomes, but their translation into clinical practice has yet to be achieved. A systematic review was performed to describe the adult populations included and enrolled in studies that evaluated the prognostic value of protein biomarkers to predict postconcussion symptoms following an $\mathrm{mTBI}$.

Data sources Searches of MEDLINE, Embase, CENTRAL, CINAHL, Web of Science, PsycBITE and PsycINFO up to October 2016.

Data selection and extraction Two reviewers independently screened for potentially eligible studies, extracted data and assessed the overall quality of evidence by outcome using the Grading of Recommendations Assessment, Development and Evaluation approach.

Results A total of 23298 citations were obtained from which 166 manuscripts were reviewed. Thirty-six cohort studies (2812 patients) having enrolled between 7 and 311 patients (median 89) fulfilled our inclusion criteria. Most studies excluded patients based on advanced age $(n=10(28 \%))$, neurological disorders $(n=20(56 \%))$, psychiatric disorders $(n=17(47 \%))$, substance abuse disorders $(n=13(36 \%))$ or previous traumatic brain injury $(n=10(28 \%))$. Twenty-one studies $(58 \%)$ used at least two of these exclusion criteria. The pooled mean age of included patients was 39.3 (SD 4.6) years old (34 studies). The criteria used to define a mTBI were inconsistent. The most frequently reported outcome was postconcussion syndrome using the Rivermead Post-Concussion Symptoms Questionnaire $(\mathrm{n}=18(50 \%))$ with follow-ups ranging from 7 days to 5 years after the mTBI. Conclusions Most studies have recruited samples that are not representative and generalisable to the $\mathrm{mTBI}$ population. These exclusion criteria limit the potential use

\section{Strengths and limitations of this study}

- This systematic review on the characteristics of patients included and enrolled in studies on the prognostic value of serum protein biomarkers for prediction of postconcussion symptoms reports important findings for researchers planning their study and for clinicians interpreting the available data.

- Strengths of this systematic review include the exhaustive search strategy performed using seven databases, the selection and data extraction conducted independently by two researchers and the registration beforehand in the Prospero database of the study protocol.

- This study is limited by the quality of the included studies as well as the unavailability of some relevant data such as some studies' inclusion criteria, exclusion criteria and clear patient demographic data.

and translation of promising serum protein biomarkers to predict postconcussion symptoms.

\section{INTRODUCTION}

Mild traumatic brain injury (mTBI) is frequently encountered by neurologists, primary care, emergency, sport medicine and rehabilitation health providers ${ }^{1}$ and accounts for approximately $80 \%$ of all TBI. ${ }^{2}$ The incidence of mTBI exceeds that of dementia, epilepsy and stroke, giving it the status of the most common brain disorder. ${ }^{3}$ However, there is still an incomplete understanding of mTBI pathophysiology that leads to suboptimal diagnosis, treatment and prognostication. ${ }^{4}$ With increasing attendance to emergency departments following 
mTBI by complex patients such as elderly, ${ }^{5}$ intoxicated patients ${ }^{67}$ and patients with psychiatric disorders, ${ }^{8}$ there is an urgent need to optimise the care of patients with mTBI.

Once considered benign, there has been increased awareness of the potential adverse consequences of mTBI. ${ }^{9}$ While $80 \%$ of patients will report at least one early postconcussion symptom, ${ }^{10}$ between $10 \%$ and $56 \%$ will exhibit persistent symptoms 3 months after an mTBI. ${ }^{11-15}$ Physical, cognitive and emotional symptoms, often described as postconcussion syndrome (PCS), that exceed the expected window of recovery have deleterious impacts on quality of life and daily functional outcome. ${ }^{16-18}$ Prognostic markers have been highlighted for cognitive, psychiatric and mortality outcomes. ${ }^{19}$ However, the authors acknowledged that evidence regarding psychiatric and mortality outcomes is limited and that little evidence exist concerning the role of biological markers in predicting the persistence of cognitive impairment after mTBI. ${ }^{19}$ Under these conditions, there is still a need to develop objective assessment and prognostication tools. Novel brain specific serum protein biomarkers have been studied to assist the prognostic evaluation after mTBI, but the translation of protein biomarker research into clinical practice to predict PCS is still pending.

Unfortunately, research in mTBI is beset with methodological challenges. Researchers are confronted with substantial heterogeneity of patients, various mechanisms of injury and a wide range of potential outcomes. ${ }^{20}{ }^{21}$ Therefore, many researchers choose to apply strict inclusion and exclusion criteria to minimise confounding by such factors and to decrease the inherent population heterogeneity. ${ }^{20}$ This approach results in improved internal validity but also inevitably limits recruitment and generalisability of results. Some populations are therefore often excluded or less likely to be enrolled in TBI studies. ${ }^{22}$ Furthermore, many methodological concerns regarding mTBI studies such as the inconsistency in mTBI definitions and the frequent inadequacy of outcome measures were highlighted in the recent synthesis performed by the International Collaboration on Mild Traumatic Brain Injury Prognosis. ${ }^{23}$ All these methodological issues further limit the translation to bedside care and might be applicable to research in the field of brain-specific biomarkers following an mTBI. Identifying which patients are not enrolled and how often they are excluded from these studies will allow to underline the generalisability of this literature and highlight gaps that future researches should aim to fill.

This systematic review aims to describe populations included or enrolled in studies on the prognostic value of protein biomarkers for prediction of postconcussion symptoms following an mTBI. The secondary objectives are to describe the mTBI definition applied in these studies as well as the outcomes evaluated.

\section{METHODS}

\section{Search strategy}

A systematic review was performed to determine the prognostic value of protein biomarkers to predict the occurrence of postconcussion symptoms following an mTBI (International Prospective Register of Systematic Reviews (PROSPERO) registration CRD42016032578). In summary, a general search strategy aiming to identify articles that assessed the association between protein biomarkers and postconcussion symptoms in traumatic brain injury (TBI) was created for seven databases (from their inception to 4 October 2016): MEDLINE, Embase, CINAHL, Cochrane Central Register of Controlled Trials, Web of Science, PsycBITE and PsycINFO using Medical Subject Headings (MeSH terms), Embase Subject Headings (EMTREE terms) and keywords for their respective database. This research used a general strategy with an additional focus on seven of the most studied and promising protein biomarkers (S-100 $\beta$ protein, neuron-specific enolase (NSE), glial fibrillar acidic protein (GFAP), ubiquitin carboxy-terminal hydrolase L1 (UCHL-1), cleaved tau (c-tau), microRNA and brain-derived neurotrophic factor (BDNF) $).{ }^{24-28}$ No language, type of study or date restriction were applied in the initial search strategy. The detailed Embase search strategy is available in online supplementary table 1. References from the included studies and narrative reviews were also scrutinised, and relevant abstracts from congress and conferences were reviewed to identify potential peer-reviewed published studies (online supplementary table 2). Authors of potentially relevant abstracts were contacted to identify potentially published studies not identified with our search strategies.

\section{Study selection}

Using EndNote (Thomson Reuters, V.X7), all the citations obtained with our search strategies on the seven databases were combined. Duplicates were removed. Independently, two reviewers (EM and P-AT) then scrutinised all citations and consecutively excluded studies using the title and abstract. Manuscripts of all potentially included studies were obtained. Studies in other language than English or French were translated into English. A third researcher (NLS) was involved in case of disagreement and was responsible for the final decision regarding the inclusion of a study.

Studies were considered eligible for inclusion when they reported the association between at least one serum protein biomarker level and at least one postconcussion symptom evaluated $\geq 7$ days following an mTBI. This duration was chosen to ensure that the outcomes represented a prognostic measure instead of a diagnostic evaluation. This study was limited to the adult ( $>16$ years old) population. Studies were excluded if they were animal studies, specific to a paediatric population, reporting on moderate or severe TBI or if the postconcussion symptom evaluation was performed $<7$ days after the mTBI or the study was not published in a peer-reviewed journal. Case reports were also excluded. 


\section{Data extraction}

Using a data collection form, two reviewers (EM and P-AT) independently collected the relevant data from every included study. Therefore, data on the manuscript (journal, publication date and authors), study characteristics (period and methods of recruitment, country(ies), type of study, number of patients included and followed, number of hospitals involved, setting, inclusion and exclusion criteria and mTBI definition), protein biomarker (assays used and characteristics, detection limits, thresholds, timing of sampling, type of sampling (venous, capillary or arterial) and number of samples), patient characteristics (age, gender, trauma mechanism and TBI severity) and the outcomes (outcome type, assessment timing and method of outcome assessment, including statistical analyses used to assess the association between protein biomarkers and outcomes) were collected. When clarification or additional information was needed, the corresponding author of the included study was contacted via email (up to three attempts).

\section{Statistical analysis and quality assessment}

Descriptive statistics were used to describe the population included and enrolled in the studies. Measures of central tendency (means and medians) and dispersion (SD) were calculated using Statistical Analysis System software (V.9.4). Main data are also presented as proportions. In 14 studies where sufficient data were available, we calculated the pooled mean age of enrolled patients and its heterogeneity $\left(\mathrm{I}^{2}\right){ }^{29}$ To be more inclusive, a pooled mean age was also calculated using a weighted average based on study sample size for 34 studies. Where possible, age mean and SD were estimated using formulae proposed by Hozo et $a l^{30}$

The quality of the evidence of the three main outcomes was evaluated using the Grading of Recommendations Assessment, Development and Evaluation (GRADE) approach (postconcussion symptoms, Glasgow Outcome Scale (GOS-E) and GOS-Extended (GOS-E) and return to work) ${ }^{31}$ Given the high heterogeneity of the outcomes evaluated and the scales used, no quality of evidence assessment was performed for the neuropsychological outcomes. This study is reported in accordance with the Preferred Reporting Items for Systematic Reviews and Meta-Analyses (PRISMA) Statement (online supplementary table 3$).^{32}$

\section{RESULTS}

\section{Characteristics of the included studies}

After removal of duplicates, the search strategy yielded 23298 unique citations. Following the assessment of titles and abstracts using our inclusion and exclusion criteria, a total of 166 manuscripts were reviewed (figure 1). Thirty-six manuscripts fulfilled our criteria and were included in the present study (table 1). Only one disagreement between the reviewers required the third researcher (NLS) to make the final decision. A total of
2812 patients were included in those studies, which individually included from 7 to 311 patients (mean 104 (SD 62), median 89). Twenty-one studies were conducted in Europe, while eight were from North America, six from Asia and one was from South America. Two studies were in German and were fully translated in English. Only eight studies $(22 \%)$ evaluated patients from multiple centres. The most frequent protein biomarker studied was the S-100 $\beta$ protein (29 studies) followed by NSE (10 studies), c-tau (4 studies), GFAP (4 studies), UCHL-1 (3 studies), BDNF (1 study) and microRNA (1 study).

\section{Inclusion and exclusion criteria in the included studies}

Age limits criteria and the age of the patients enrolled in the studies are illustrated in the online supplementary figure 1. Regarding the inclusion criteria, an upper age limit was used in 10 studies (28\%). Therefore, patients $\geq 65$ years old were excluded in seven studies $(19 \%)$, while those aged $\geq 85$ years old were excluded in three more studies (total 10 studies, 28\%). Across studies, the oldest patient enrolled ranged from 40 to 94 years old. The pooled mean age in the 14 studies with data on SD was 38.7 (SD 5.3) years old (18 studies) and was highly heterogeneous $\left(\mathrm{I}^{2} 97 \%\right)$. In 34 studies, the pooled mean age was 39.3 (SD 4.6) years old.

The most frequent exclusion criteria were neurological disorders, psychiatric disorders, trauma to another body region, substance abuse disorders and previous TBI (table 2). Twenty-one studies (58\%) used at least two of these exclusion criteria. Medical comorbidities were infrequently used as exclusion criteria. Ten studies $(28 \%)$ did not report any exclusion criteria and were therefore considered as having no exclusion criteria.

\section{mTBI definitions in the included studies}

The mTBI definitions used were not standardised (table 3). The Glasgow Coma Scale (GCS) was a criterion in 31 studies $(86 \%)$ using either GCS 13-15 (23 studies $(64 \%))$, GCS 14-15 (7 studies $(19 \%)$ ) or GCS 15 only (1 study $(3 \%))$. Other criteria such as loss of consciousness (LOC), post-traumatic amnesia (PTA) and focal neurological deficit were inconsistently used to define mTBI. Three $(8.3 \%)$, six $(16.7 \%)$ and one $(2.8 \%)$ studies used definitions promoted by the American College of Emergency Physician/Centers for Disease Control and Prevention, ${ }^{33}$ the American Congress of Rehabilitation Medicine ${ }^{34}$ and the European Federation of Neurological Societies, ${ }^{35}$ respectively.

\section{Outcomes presented in the included studies}

Table 4 presents the outcomes evaluated. The most frequently evaluated outcome was PCS in 18 studies (50\%). The Rivermead Post-Concussion Symptoms Questionnaire was the most used scale. Table 5 presents the number of symptoms required to define the presence of a PCS in the different studies. The number of symptoms used to define a positive PCS ranged between one and five with only 10 studies ( $28 \%$ ) using $\geq 3$ criteria. Among 


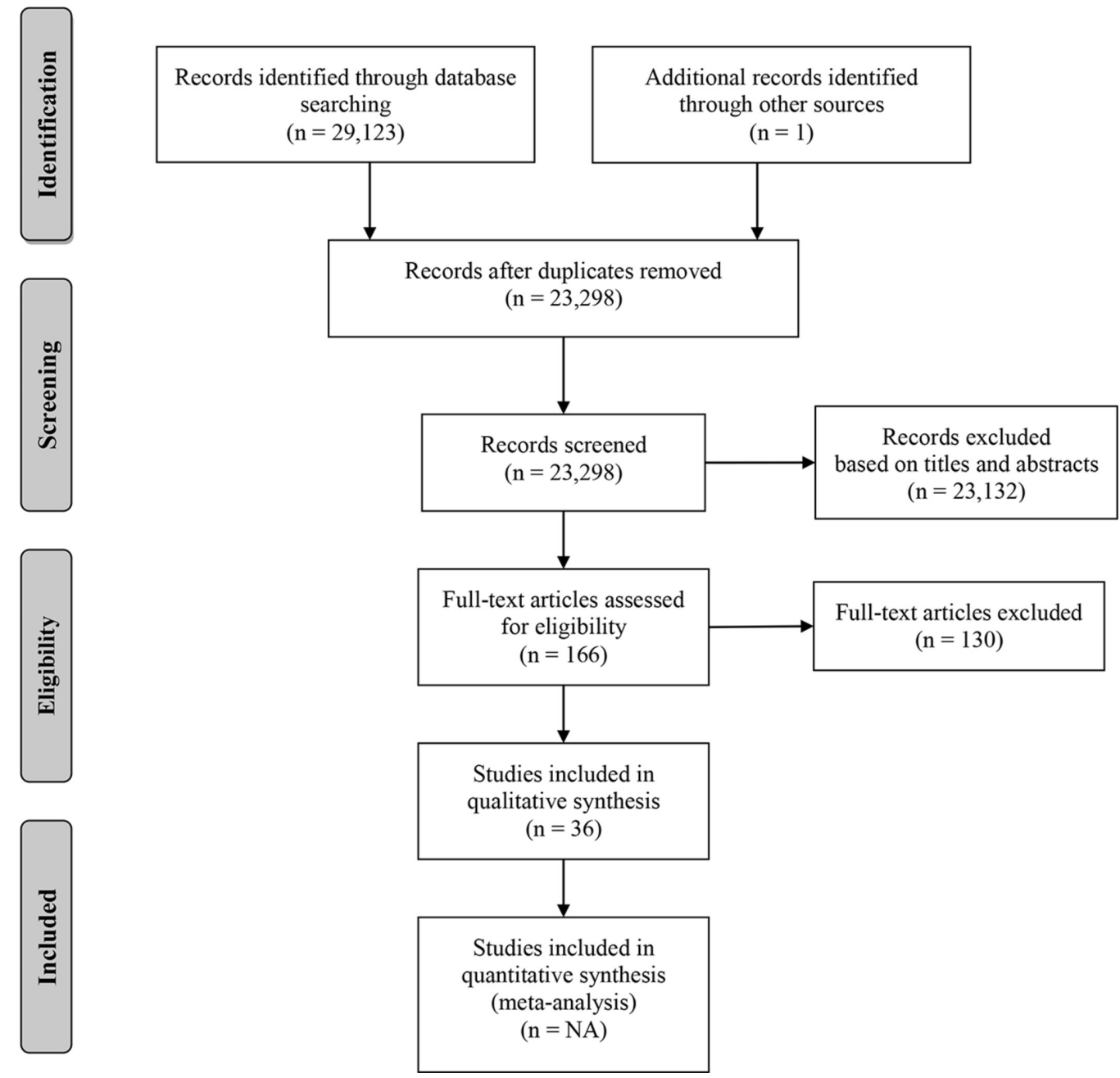

Figure 1 PRISMA flow diagram of included studies. Preferred Reporting Items for Systematic Reviews and Meta-Analyses.

the 36 studies, there were 48 outcome evaluations, and the duration between the mTBI and the outcome assessment was $>3$ months in only $22(46 \%)$ of them. Six studies used outcomes that were unlikely to detect subtle impairment after an mTBI such as the GOS or the GOS-E. ${ }^{36}$

\section{Assessment of outcomes in the included studies}

Half of studies used multivariate regression models to assess the association between protein biomarkers at the initial visit and the presence of outcomes at follow-up. Eleven studies (30.5\%) used area under the receiver operating characteristic curve (AUROC) analyses to assess the potential prognostic value of biomarkers to predict the occurrence of outcomes in patients with an mTBI. Among these, only one compared the area under the curve obtained using the protein biomarker alone to that obtained with a multivariate model including clinical factors.

\section{Quality of the evidence}

Using the GRADE approach, the quality of evidence was evaluated as low or insufficient for the most frequently studied outcomes (table 6). Various neuropsychological assessments were grouped together in table 4, but given the heterogeneity of the neuropsychological tests used and the analytic methods, no GRADE assessment was performed for this outcome.

\section{DISCUSSION}

Our systematic review highlights the selected patient populations in previously published reports. Most studies have restricted the inclusion of patients based on advanced age (28\%), neurological disorders (56\%), psychiatric disorders (47\%), substance abuse disorders $(36 \%)$ or previous TBI $(28 \%)$. The mean age of enrolled patients was only 38.7 years old. There are also important variations in the definitions of $\mathrm{mTBI}$ and in outcomes evaluated. The criteria used to define the occurrence of a positive PCS using the Rivermead Post-Concussion Symptoms Questionnaire ranged between one and five symptoms. These results impact on the generalisability and clinical applicability of the study findings on protein biomarkers and other prognostic tools following mTBI.

The epidemiology of TBI has evolved with increasing numbers of complex patients consulting for their injury, such as elderly ${ }^{37}$ and patients with substance 
Table 1 Characteristics of included studies

\begin{tabular}{|c|c|c|c|c|c|c|}
\hline First author & $\begin{array}{l}\text { Year of study } \\
\text { publication }\end{array}$ & Countries & $\begin{array}{l}\text { Number of } \\
\text { hospitals }\end{array}$ & $\begin{array}{l}\text { Number of } \\
\text { patients } \\
\text { included }\end{array}$ & Biomarkers assessed & $\begin{array}{l}\text { Multivariate* } \\
\text { AUROC† }\end{array}$ \\
\hline Ingebrigtsen ${ }^{58}$ & 1995 & Norway & 1 & 50 & $S-100 \beta$ & $x / x$ \\
\hline Waterloo 59 & 1997 & Norway & 1 & 7 & S-100ß & $x / x$ \\
\hline Ingebrigtsen ${ }^{60}$ & 1999 & Norway & 1 & 50 & S-100 $\beta$ & $x / x$ \\
\hline Herrmann 62 & 2001 & Germany & 1 & 69 & S-100 $\beta$, NSE & $\checkmark / S$ \\
\hline De Kruijk ${ }^{63}$ & 2002 & Netherlands & 1 & 107 & S-100 $\beta$, NSE & $\checkmark / x$ \\
\hline Townend $^{64}$ & 2002 & UK & 4 & 148 & S-100 $\beta$ & $d / 2$ \\
\hline de Boussard ${ }^{68}$ & 2005 & Sweden & 3 & 122 & $S-100 \beta$ & $x / x$ \\
\hline Stålnacke ${ }^{69}$ & 2005 & Sweden & 1 & 88 & S-100 $\beta$, NSE & $S / X$ \\
\hline Stapert ${ }^{70}$ & 2005 & The Netherlands & 1 & 50 & S-100 $\beta$ & $x / x$ \\
\hline Bazarian $^{71}$ & 2006 (BI) & USA & 1 & 35 & S-100 $\beta$, C-tau & $x / \sqrt{ }$ \\
\hline Bazarian $^{72}$ & 2006 (RNN) & USA & 1 & 96 & $S-100 \beta$ & $x / S$ \\
\hline Bulut $^{73}$ & 2006 & Turkey & 1 & 60 & C-tau & $x / x$ \\
\hline Naeimi $^{74}$ & 2006 & Austria & 1 & 45 & S-100 $\beta$, NSE & $x / x$ \\
\hline Sojka ${ }^{75}$ & 2006 & Sweden & 1 & 98 & S-100ß, NSE & $\checkmark / x$ \\
\hline Müller ${ }^{81}$ & 2009 & Norway & 1 & 93 & S-100 $\beta$ & $\checkmark / x$ \\
\hline Kleinert $^{82}$ & 2010 & Germany & 1 & 73 & S-100ß & $x / x$ \\
\hline Meric $^{83}$ & 2010 & Turkey & 1 & 80 & NSE & $x / \sqrt{ }$ \\
\hline $\begin{array}{l}\text { Topolovec- } \\
\text { Vranic }^{84}\end{array}$ & 2011 & Canada & 1 & 141 & S-100 $\beta$, NSE & $S / S$ \\
\hline Metting $^{85}$ & 2012 & The Netherlands & 1 & 94 & S-100 $\beta$, GFAP & $\sqrt{ } / x$ \\
\hline Okonkwo ${ }^{86}$ & 2013 & USA & 3 & 215 & GFAP & $S / S$ \\
\hline Abbasi $^{87}$ & 2014 & Iran & 2 & 109 & S-100ß & $x / x$ \\
\hline Diaz-Arrastia $^{88}$ & 2014 & USA & 3 & 206 & GFAP, UCHL-1 & $x / 2$ \\
\hline $\mathrm{Ryb}^{89}$ & 2014 & USA & 1 & 150 & S-100 $\beta$ & $\sqrt{ } / \mathfrak{S}$ \\
\hline Heidari ${ }^{90}$ & 2015 & Iran & 1 & 176 & $S-100 \beta$ & $\sqrt{ } / x$ \\
\hline Dey $^{91}$ & 2016 & India & 1 & 20 & S-100 $\beta$, UCHL-1 & $x / x$ \\
\hline Korley $^{28}$ & 2016 & USA & 2 & 311 & C-tau, GFAP, UCHL-1 & $2 / 2$ \\
\hline Yang $^{92}$ & 2016 & China & 1 & 76 & miR-93, miR-191, miR-499 & $x / x$ \\
\hline
\end{tabular}

${ }^{*}$ The association between protein biomarker(s) and outcome(s) was assessed using a multivariate regression model.

†The prognostic value of protein biomarker(s) was assessed using an area under the receiver operating characteristic curve (AUROC).

$\mathrm{BI}$, brain injury; C-tau, cleaved tau; GFAP, glial fibrillar acidic protein; miR, microRNA; NSE, neuron-specific enolase; RNN, restorative neurology and neuroscience; UCHL-1, ubiquitin carboxy-terminal hydrolase L1. 
Table 2 Exclusion criteria used in the included studies

\begin{tabular}{ll}
\hline Exclusion criteria & $\begin{array}{l}\text { Number of studies } \\
\text { (n, \%) }\end{array}$ \\
\hline Neurological disorder & $20(55.6)$ \\
\hline $\begin{array}{l}\text { Psychiatric disorder } \\
\text { Significant trauma to another body }\end{array}$ & $17(47.2)$ \\
region than the head & $147.2)$ \\
\hline $\begin{array}{l}\text { Substance abuse (drug or alcohol) } \\
\text { Previous traumatic brain injury }\end{array}$ & $14(38.8)$ \\
\hline Alcohol intoxication & $10(27.8)$ \\
\hline Renal impairment & $9(25)$ \\
\hline Cardiac disease & $3(8.3)$ \\
\hline
\end{tabular}

abuse, psychiatric or neurological disorders. ${ }^{6}$ Intoxi- $^{8}$ cated patients also often present with altered conscious state raising the possibility of TBI and complicating initial clinical assessment. ${ }^{38}{ }^{39}$ Patients with previous TBI are also of concern given the complications of repetitive TBI. ${ }^{40}$ All these patients pose a challenge to the clinician in terms of assessment of injury severity and prognosis. Moreover, these preinjury factors are known to predispose to the development of persistent postconcussion symptoms leading to poorer functional outcomes. ${ }^{41-45}$ In a large retrospective cohort study of patients with suspected TBI, patients were frequently intoxicated with alcohol (20\%) or had a psychiatric $(25 \%)$ or neurological disorders $(25 \%){ }^{22}$ These patients were excluded in, respectively, $25 \%, 47 \%$ and $56 \%$ of the studies included in our systematic review. Moreover, geriatric patients represent a constantly growing proportion of the trauma population as the world is ageing. ${ }^{46}{ }^{47}$ The absolute incidence of TBI among the geriatric patients is rising as a result of the increased life expectancy and mobility. ${ }^{5}$ Advanced age was an exclusion criteria in 10 studies $(28 \%)$, but the patients enrolled were mostly young with a mean age of only 38.7 (SD 5.3) years old. Recent large TBI epidemiological studies ${ }^{48} 49$ showed that more than $40 \%$ of the mTBI population are older than 50 years, and the median age of patients is at least 44 years. ${ }^{50}$ Geriatric patients therefore seem under-represented in our included studies despite the fact that they have a poorer functional outcome with an increased occurrence of post-concussion symptoms. ${ }^{51}$ The effect of age on the circulating blood-based biomarker is controversial. ${ }^{52}$ Geriatric patients often have medical comorbidities that can potentially impact the biomarker's production, metabolism and clearance, thus altering its baseline circulating serum level and its release following an mTBI. Interestingly, patients with renal impairment were excluded in only three studies $(8 \%)$ even though some medical comorbidities might represent a more robust exclusion criteria than age alone.

Selection bias is common, and strict enrolment criteria have been associated with exclusion of up to $95 \%$ of the general mTBI population. ${ }^{20} 22$ Therefore, patients
Table 3 Criteria used to define mild traumatic brain injury (mTBI) in the included studies

\begin{tabular}{ll}
\hline Criteria & $\begin{array}{l}\text { Number of } \\
\text { studies }(\mathbf{n}, \%)\end{array}$ \\
\hline Glasgow Coma Scale (GCS) & \\
$13-15$ & $23^{*}(63.8)$ \\
$14-15$ & $7(19.4)$ \\
15 & $1(2.8)$ \\
NR & $5 \dagger(13.9)$ \\
Loss of consciousness (LOC) & \\
$<10$ min & $4(11.1)$ \\
$<15$ min & $5(13.9)$ \\
$<30$ min & $9^{*}(25)$ \\
No duration & $8 \dagger(22.2)$ \\
No use of LOC & $10(27.8)$ \\
Post-traumatic amnesia (PTA) & \\
$<15$ min & $1(2.8)$ \\
$<30$ min & $0(0)$ \\
$<60$ min & $4^{*}(11.1)$ \\
$<24$ hours & $3(8.3)$ \\
No duration & $7 \dagger(19.4)$ \\
No use of PTA & $21(58.3)$ \\
\hline
\end{tabular}

Initial altered mental state

Yes

Absence of focal neurology deficit

Yes

$14(38.9)$

Triaged to non-contrast head CT using the $3 \dagger$ (8.3) (ACEP/CDC) evidence-based joint practice guideline

$\begin{array}{ll}\text { Use of the American Congress of } & 6(16.7) \\ \text { Rehabilitation Medicine definition (1993) } & \\ \text { Use of European Federation of } & 1^{*}(2.8) \\ \text { Neurological Societies definition (2002) } & \end{array}$

*Heidari et al ${ }^{9090}$ used the following mTBI definition: (1) a GCS score of 13-14; (2) a GCS score of 15 with LOC $<30 \mathrm{~min}$, PTA < 1 hour; or (3) a GCS score of 15 without LOC or PTA. †Korley et $\mathrm{al}^{2828}$ presented three different cohorts with different inclusion criteria. Only the mTBI definition of the case cohort is presented in the table.

$\ddagger$ ACEP, American College of Emergency Physicians; CDC, Centers for Disease Control and Prevention.

with premorbid conditions remain poorly studied despite their unfavourable prognosis and increased risk of disabilities. ${ }^{41} 42$ Also, the association between the protein biomarker and the outcome in patients with premorbid conditions might differ from the association with healthier patients, therefore limiting the potential to draw clinical conclusions. Future studies should aim to maximise the inclusion and the recruitment of these clinically relevant patients. To facilitate the inclusion of these patients, studies addressing the influence of age, intoxication and previous neurological disorder on 
Table 4 Outcome evaluated in the included studies

\begin{tabular}{ll}
\hline Outcome evaluated & Number of studies (n, \%) \\
\hline Postconcussion syndrome & $18(50)$ \\
\hline Neuropsychological evaluation & $9(25)$ \\
\hline GOS-E; GOS & $5(13.8) ; 4(11.1)$ \\
\hline Return to work & $4(11.1)$ \\
\hline Headache & $3(8.3)$ \\
\hline Life satisfaction & $2(5.6)$ \\
\hline RHFUQ & $2(5.6)$ \\
\hline Anxiety or depression & $1(2.7)$ \\
\hline Daily activity functioning & $1(2.7)$ \\
\hline Olfactory function & $1(2.7)$ \\
\hline Post-traumatic related stress & $1(2.7)$ \\
\hline Quality of life & $1(2.7)$ \\
\hline SF-36 & $1(2.7)$ \\
\hline Duration between mild TBI & Assessments \\
and outcome assessment & (n=48 outcomes) (n, \%) \\
\hline 7 days & $3(6.3)$ \\
\hline 14 days & $6(12.5)$ \\
\hline month & $6(12.5)$ \\
\hline 1.1-3 months & $11(23)$ \\
\hline 3.1-6 months & $11(23)$ \\
\hline $6.1-12$ months & $6(12.5)$ \\
\hline 12.1-18 months & $4(8.2)$ \\
\hline 18.1 months & $1(2)$ \\
\hline
\end{tabular}

GOS, Glasgow Outcome Scale; GOS-E, Glasgow Outcome Scale-Extended; RHFUQ, Rivermead Head Injury Follow-up Questionnaire; SF-36, Acute Medical Outcomes F6-36v2 Health Survey; TBI, traumatic brain injury.

protein biomarker baseline level and the kinetic modelling of protein biomarker release in the serum following an $\mathrm{mTBI}$ are required.

The definition of mTBI was widely variable between the studies often limiting the comparability of studies. While GCS was almost universally included as a criterion, other criteria such as PTA, LOC and neuroimaging results were inconsistently used. mTBI is a heterogeneous group with a wide range of 'severity'. The symptom-based GCS

Table 5 Definition of postconcussion syndrome (PCS)

\begin{tabular}{lll}
\hline Scale used & $\begin{array}{l}\text { Number of positive } \\
\text { symptoms to define } \\
\text { the presence of a PCS }\end{array}$ & $\begin{array}{l}\text { Number of } \\
\text { studies }(\mathbf{n}, \%)\end{array}$ \\
\hline Rivermead Post- & $\geq 1$ & $3(17)$ \\
Concussion & $\geq 2$ & $1(5.5)$ \\
Symptoms & $\geq 3$ & $5(28)$ \\
Questionnaire & $\geq 4$ & $1(5.5)$ \\
& $\geq 5$ & $2(11)$ \\
& Not specified & $6(33)$ \\
\hline
\end{tabular}

classification often fails to demonstrate the whole spectrum of severity. The diagnostic criteria can be unreliable and overlap many conditions such as dementia, delirium or intoxication, and the presence of confounding factors during the initial assessment is frequent. ${ }^{8}$

One major limitation to our understanding of mTBI is the lack of universal definition of the outcomes evaluated. ${ }^{53}$ Most patients recover completely but for those affected by persistent symptoms, there are controversies about the nomenclature and definitions associated with postconcussion symptoms and PCS. ${ }^{54}$ This is particularly noticeable in our systematic review as the diagnosis criteria of PCS was highly variable ranging from one to more than five criteria on the Rivermead Post-Concussion Symptoms Questionnaire to determine the presence or the absence of PCS. The timing of outcome evaluation was also variable ranging from 7 days to more than 5 years. PCS is a complex constellation of symptoms with a significant variability between individuals. Since most symptoms are subjective, there is a high risk of misdiagnosis ${ }^{55}$ and we are still unable to predict the occurrence of PCS. Biomarkers are promising to help predict the recovery and the risk of persistent PCS, but well-designed confirmatory studies that address the methodological limitations are needed to enhance our knowledge of mTBI consequences. ${ }^{19}$ The lack of standardisation in the definition of the outcomes contributes to impede the translation from research to daily bedside care in the field of brain-specific biomarkers. Another shortcoming that might partly explain the difficulty of using protein biomarkers to predict postconcussion symptoms are that these symptoms are not specific to mTBI and are prevalent both in the general population and after non-head injuries. $^{56}$

In addition to the aforementioned shortcomings, a methodological issue that possibly limits the translation of protein biomarkers from research to everyday care is the statistical methods used to assess the value of these biomarkers. Showing that a given protein biomarker sampled at the initial admission is correlated with outcomes at follow-up is certainly valuable, but this result in itself remains insufficient to inform patient management. Guidelines and clinical decision rules aiming to rule out unnecessary neuroimaging or to identify patients who are at high risk of experiencing persistent symptoms following their mTBI require operational tools. To this end, practicable information on the prognostic (discriminative) value of protein biomarkers is necessary. In our systematic review, only $30 \%$ of studies performed AUROC analyses, and only one study compared the AUC obtained using the protein biomarker alone with that obtain with a multivariable model. Unless protein biomarkers are shown to add significant prognostic value over and above clinical factors readily available in clinical settings, they are unlikely to be integrated into daily clinical practice. However, there are numerous other potential benefits to study protein biomarkers after an mTBI. ${ }^{57}$ In addition to improving the initial prognostication, the use of 
Table 6 Outcomes quality of evidence according to the Grades of Recommendation, Assessment, Development, and Evaluation (GRADE) approach

\begin{tabular}{|c|c|c|c|c|}
\hline Outcomes & $\begin{array}{l}\text { Number of studies } \\
\text { (number of } \\
\text { patients) }\end{array}$ & Design & Findings and direction & GRADE \\
\hline $\begin{array}{l}\text { Postconcussion } \\
\text { symptoms }\end{array}$ & $\begin{array}{l}18 \text { studies } \\
(n=2048)\end{array}$ & Observational & $\begin{array}{l}\text { Important heterogeneity in populations enrolled, } \\
\text { definitions of outcome variables and evaluation duration. } \\
\text { Only four associations between postconcussion } \\
\text { symptoms and a biomarker were statistically significant. } \\
\text { Only eight studies used multivariate regression analyses } \\
\text { and Cls were often large. }\end{array}$ & Low \\
\hline GOS-E and GOS & $\begin{array}{l}\text { Nine studies } \\
(n=1235)\end{array}$ & Observational & $\begin{array}{l}\text { Slight discrepancies in definitions, wide differences } \\
\text { in populations enrolled, methods quality as well as in } \\
\text { evaluation duration and inconsistencies in associations } \\
\text { (only three were significant), their direction and strength. }\end{array}$ & Insufficient \\
\hline Return to work & $\begin{array}{l}\text { Four studies } \\
(n=432)\end{array}$ & Observational & $\begin{array}{l}\text { Slight discrepancies in definitions and reporting but } \\
\text { considerable differences in evaluation duration ( } 1 \text { week- } \\
1 \text { year). Only one study showed a significant association } \\
\text { with increased S-100 } \beta \text { protein serum level. }\end{array}$ & Insufficient \\
\hline
\end{tabular}

GOS, Glasgow Outcome Scale; GOS-E, Glasgow Outcome Scale-Extended.

biomarkers could help making the diagnosis, determine more accurately the need for neuroimaging, evaluating the disease progression, determining the safe moment to return to sport or activities and might be used as a surrogate assessment tool for investigational treatments. ${ }^{26} 27$ As mTBI diagnostic criteria are subjective, non-specific and overlap other conditions, a biomarker level could alleviate the paucity around the initial presentation and represent an objective assessment tool.

\section{Strengths and limitations}

Our study has several limitations. We looked both at the characteristics of the inclusion/exclusion criteria and the patients enrolled. The absence of exclusion criteria does not mean that some subgroups of patient will be enrolled and often studies failed to present the number of patients screened and approached to be enrolled. Therefore, we can expect that our review underestimates the poor representation of subgroups such as patients with substance abuse, psychiatric and neurological disorders. Ten studies did not report any exclusion criteria and were considered as having no exclusion criteria, but this might be a misinterpretation, thus making the underestimation even more likely. We have however used high methodological standards to perform our systematic review. We have completed an exhaustive unrestrictive search strategy using seven databases and screened 23298 citations. Studies were researched, and data were extracted independently by two reviewers. This study is reported in accordance with the recommended PRISMA Statement.

\section{CONCLUSION}

The patients included and enrolled in studies on the prognostic value of protein biomarkers following mTBI are not representative of the mTBI population. Subgroups such as elderly, patients with neurological, psychiatric and substance abuse disorders and patients with previous TBI are often excluded and poorly represented even though they are at high risk of postconcussion symptoms and associated disabilities. The lack of standardisation of definitions further impedes the translation from research to everyday patient care. Broader inclusion criteria and standardised definitions, particularly mTBI and PCS, are required to maximise the generalisability and the translation to bedside care of the promising brain-specific biomarkers.

\section{Author affiliations}

${ }^{1}$ Axe Santé des Populations et Pratiques Optimales en Santé, Unité de recherche en Traumatologie - Urgence - Soins Intensifs, Centre de recherche du CHU de Québec, Université Laval, Quebec, Canada

${ }^{2}$ Département de Médecine Familiale et Médecine d'Urgence, Faculté de Médecine, Université Laval, Quebec, Canada

${ }^{3}$ Emergency and Trauma Centre, The Alfred Hospital, Alfred Health, Melbourne, Australia

${ }^{4}$ School of Public Health and Preventive Medicine, Monash University, Melbourne, Australia

${ }^{5}$ Axe Santé des Populations et Pratiques Optimales en Santé, Unité de recherche en Vieillissement, Centre de recherche du CHU de Québec, Université Laval, Quebec,

Canada

${ }^{6}$ Centre Interdisciplinaire de Recherche en Réadaptation et Intégration Sociale (CIRRIS), Quebec, Canada

${ }^{7}$ Research-Institute, McGill University Health Centre, Quebec, Canada

${ }^{8}$ Centre de recherche interdisciplinaire en réadaptation du Montréal métropolitain (CRIR), Quebec, Canada

${ }^{9}$ National Trauma Research Institute, The Alfred Hospital, Melbourne, Victoria, Australia

Contributors EM has had the original idea for this study. EM, P-AT and NLS conceived the study's design and protocol with support, input and oversight from ME, MCO, ÉDG, BM and PC. EM and P-AT elaborated the original database search strategy. EM and P-AT performed the study selection and data extraction with oversight from ME, M-CO, ÉDG, PC and NLS. PAT prepared the data for statistical analysis. Statistical analysis plan was elaborated by ME, BM and NLS. EM and P-AT wrote the manuscript first draft. All authors contributed to the manuscript revision, and they all approved the final submitted version. All authors are accountable for all aspects of this study. 
Funding NLS has received a grant from le Fonds de Recherche du Québec Santé (FRQ-S \#30598, Consortium pour le développement de la recherche en traumatologie - Volet 4). EM has obtained a fellowship in clinical research grant from FRQ-S (\#32058).

Competing interests None declared.

Ethics approval Research Ethics Review Board of the Alfred Hospital, Melbourne, Australia (Project 299/16).

Provenance and peer review Not commissioned; externally peer reviewed.

Data sharing statement № additional data are available.

Open Access This is an Open Access article distributed in accordance with the Creative Commons Attribution Non Commercial (CC BY-NC 4.0) license, which permits others to distribute, remix, adapt, build upon this work non-commercially, and license their derivative works on different terms, provided the original work is properly cited and the use is non-commercial. See: http://creativecommons.org/ licenses/by-nc/4.0/

(C) Article author(s) (or their employer(s) unless otherwise stated in the text of the article) 2017. All rights reserved. No commercial use is permitted unless otherwise expressly granted.

\section{REFERENCES}

1. Langlois JA, Marr A, Mitchko J, et al. Tracking the silent epidemic and educating the public: CDC's traumatic brain injury-associated activities under the TBI Act of 1996 and the Children's Health Act of 2000. J Head Trauma Rehabil 2005;20:196-204.

2. Ruff R. Two decades of advances in understanding of mild traumatic brain injury. J Head Trauma Rehabil 2005;20:5-18.

3. Mondello S, Schmid K, Berger RP, et al. The challenge of mild traumatic brain injury: role of biochemical markers in diagnosis of brain damage. Med Res Rev 2014;34:503-31.

4. Katz DI, Cohen SI, Alexander MP. Mild traumatic brain injury. Handb Clin Neurol 2015;127:131-56.

5. Roozenbeek B, Maas Al, Menon DK. Changing patterns in the epidemiology of traumatic brain injury. Nat Rev Neurol 2013;9:231-6.

6. Brennan JH, Bernard S, Cameron PA, et al. Ethanol and isolated traumatic brain injury. J Clin Neurosci 2015;22:1375-81.

7. Hamilton BH, Sheth A, McCormack RT, et al. Imaging of frequent emergency department users with alcohol use disorders. J Emerg Med 2014;46:582-7.

8. Furger RE, Nelson LD, Brooke Lerner E, et al. Frequency of Factors that Complicate the Identification of Mild Traumatic Brain Injury in Level I Trauma Center Patients. Concussion 2016;1.

9. McMillan TM, McSkimming P, Wainman-Lefley J, et al. Long-term health outcomes after exposure to repeated concussion in elite level: rugby union players. J Neurol Neurosurg Psychiatry 2017;88:505-11.

10. Boake C, McCauley SR, Levin HS, et al. Diagnostic criteria for postconcussional syndrome after mild to moderate traumatic brain injury. J Neuropsychiatry Clin Neurosci 2005;17:350-6.

11. Kashluba S, Paniak C, Blake T, et al. A longitudinal, controlled study of patient complaints following treated mild traumatic brain injury. Arch Clin Neuropsychol 2004;19:805-16.

12. Holm L, Cassidy JD, Carroll LJ, et al. Summary of the WHO Collaborating Centre for Neurotrauma Task Force on Mild Traumatic Brain Injury. J Rehabil Med 2005;37:137-41.

13. Fung $M$, Willer B, Moreland D, et al. A proposal for an evidencedbased emergency department discharge form for mild traumatic brain injury. Brain Inj 2006:20:889-94.

14. Meares S, Shores EA, Taylor AJ, et al. Mild traumatic brain injury does not predict acute postconcussion syndrome. J Neurol Neurosurg Psychiatry 2008;79:300-6.

15. McLean SA, Kirsch NL, Tan-Schriner CU, et al. Health status, not head injury, predicts concussion symptoms after minor injury. Am J Emerg Med 2009;27:182-90.

16. Sirois MJ, Émond M, Ouellet MC, et al. Cumulative incidence of functional decline after minor injuries in previously independent older Canadian individuals in the emergency department. J Am Geriatr Soc 2013;61:1661-8.

17. Ponsford J, Cameron P, Fitzgerald M, et al. Long-term outcomes after uncomplicated mild traumatic brain injury: a comparison with trauma controls. J Neurotrauma 2011;28:937-46.

18. Brousseau AA, Émond M, Sirois MJ, et al. Comparison of functional outcomes in elderly who have sustained a minor trauma with or without head injury: a prospective multicenter cohort study. CJEM 2016;9:1-9.
19. Carroll LJ, Cassidy JD, Cancelliere C, et al. Systematic review of the prognosis after mild traumatic brain injury in adults: cognitive, psychiatric, and mortality outcomes: results of the International Collaboration on Mild Traumatic Brain Injury Prognosis. Arch Phys Med Rehabil 2014;95:S152-S173

20. Luoto TM, Tenovuo O, Kataja A, et al. Who gets recruited in mild traumatic brain injury research? J Neurotrauma 2013;30:11-16.

21. Maas Al, Marmarou A, Murray GD, et al. Clinical trials in traumatic brain injury: current problems and future solutions. Acta Neurochir Supp/ 2004;89:113-8.

22. Isokuortti H, Iverson GL, Kataja A, et al. Who Gets Head Trauma or Recruited in Mild Traumatic Brain Injury Research? J Neurotrauma 2016;33:232-41.

23. Kristman VL, Borg J, Godbolt AK, et al. Methodological issues and research recommendations for prognosis after mild traumatic brain injury: results of the International Collaboration on Mild Traumatic Brain Injury Prognosis. Arch Phys Med Rehabil 2014;95:S265-S277.

24. Begaz T, Kyriacou DN, Segal J, et al. Serum biochemical markers for post-concussion syndrome in patients with mild traumatic brain injury. J Neurotrauma 2006;23:1201-10.

25. Jeter CB, Hergenroeder GW, Hylin MJ, et al. Biomarkers for the diagnosis and prognosis of mild traumatic brain injury/concussion. $J$ Neurotrauma 2013;30:657-70.

26. Zetterberg H, Smith DH, Blennow K. Biomarkers of mild traumatic brain injury in cerebrospinal fluid and blood. Nat Rev Neurol 2013:9:201-10.

27. Kulbe JR, Geddes JW. Current status of fluid biomarkers in mild traumatic brain injury. Exp Neurol 2016;275:334-52.

28. Korley FK, Diaz-Arrastia R, Wu AH, et al.Circulating Brain-Derived Neurotrophic Factor Has Diagnostic and Prognostic Value in Traumatic Brain Injury. J Neurotrauma 2016;33:215-25.

29. Neyeloff JL, Fuchs SC, Moreira LB. Meta-analyses and Forest plots using a microsoft excel spreadsheet: step-by-step guide focusing on descriptive data analysis. BMC Res Notes 2012;5:52.

30. Hozo SP, Djulbegovic B, Hozo I. Estimating the mean and variance from the median, range, and the size of a sample. BMC Med Res Methodol 2005;5:13.

31. Atkins D, Best D, Briss PA, et al. Grading quality of evidence and strength of recommendations. BMJ 2004;328:1490.

32. Liberati A, Altman DG, Tetzlaff J, et al. The PRISMA statement for reporting systematic reviews and meta-analyses of studies that evaluate healthcare interventions: explanation and elaboration. $B M J$ 2009;339:b2700.

33. Jagoda AS, Bazarian JJ, Bruns JJ, et al.Clinical policy: neuroimaging and decisionmaking in adult mild traumatic brain injury in the acute setting. Ann Emerg Med 2008;52:714-48.

34. American Congress of Rehabilitation. Definition of mild traumatic brain injury: Report of the Mild Traumatic Brain Injury Committee of the head Injury Interdisciplinary Special Interest Group of the American Congress of Rehabilitation Medicine. J Head Trauma Rehabil 1993;8:86-7.

35. Vos PE, Battistin L, Birbamer G, et al. EFNS guideline on mild traumatic brain injury: report of an EFNS task force. Eur $\mathrm{J}$ Neurol 2002:9:207-19.

36. Levin HS, Boake C, Song J, et al. Validity and sensitivity to change of the extended Glasgow Outcome Scale in mild to moderate traumatic brain injury. J Neurotrauma 2001;18:575-84.

37. Albrecht JS, Hirshon JM, McCunn M, et al. Increased Rates of Mild Traumatic Brain Injury Among Older Adults in US Emergency Departments, 2009-2010. J Head Trauma Rehabil 2015.

38. Rønning P, Gunstad PO, Skaga NO, et al. The impact of blood ethanol concentration on the classification of head injury severity in traumatic brain injury. Brain Inj 2015;29:1648-53.

39. Nunn J, Erdogan M, Green RS. The prevalence of alcohol-related trauma recidivism: A systematic review. Injury 2016;47:551-8.

40. Stocchetti N, Zanier ER. Chronic impact of traumatic brain injury on outcome and quality of life: a narrative review. Crit Care 2016;20:148.

41. Kim YJ. A systematic review of factors contributing to outcomes in patients with traumatic brain injury. J Clin Nurs 2011;20:1518-32.

42. King NS. A systematic review of age and gender factors in prolonged post-concussion symptoms after mild head injury. Brain Inj 2014;28:1639-45.

43. Gould KR, Ponsford JL, Johnston L, et al. Relationship between psychiatric disorders and 1-year psychosocial outcome following traumatic brain injury. J Head Trauma Rehabil 2011;26:79-89.

44. Donnell AJ, Kim MS, Silva MA, et al. Incidence of postconcussion symptoms in psychiatric diagnostic groups, mild traumatic brain injury, and comorbid conditions. Clin Neuropsychol 2012;26:1092-101. 
45. Ponsford J, Cameron P, Fitzgerald M, et al. Predictors of postconcussive symptoms 3 months after mild traumatic brain injury. Neuropsychology 2012;26:304-13.

46. Mercier E, Mitra B, Cameron PA. Challenges in assessment of the mild traumatic brain injured geriatric patient. Injury 2016;47:985-7.

47. Ramanathan DM, McWilliams N, Schatz P, et al. Epidemiological shifts in elderly traumatic brain injury: 18-year trends in Pennsylvania. J Neurotrauma 2012;29:1371-8.

48. Stocchetti N, Paternò R, Citerio G, et al. Traumatic brain injury in an aging population. $J$ Neurotrauma 2012;29:1119-25.

49. Andriessen TM, Horn J, Franschman G, et al. Epidemiology, severity classification, and outcome of moderate and severe traumatic brain injury: a prospective multicenter study. J Neurotrauma 2011;28:2019-31.

50. Adams SD, Cotton BA, McGuire MF, et al. Unique pattern of complications in elderly trauma patients at a Level I trauma center. $J$ Trauma Acute Care Surg 2012;72:112-8.

51. McIntyre A, Mehta S, Janzen S, et al. A meta-analysis of functional outcome among older adults with traumatic brain injury. NeuroRehabilitation 2013;32:409-14.

52. Calcagnile $\mathrm{O}$, Holmén $\mathrm{A}$, Chew M, et al. S100B levels are affected by older age but not by alcohol intoxication following mild traumatic brain injury. Scand J Trauma Resusc Emerg Med 2013;21:52.

53. Losoi H, Silverberg ND, Wäljas M, et al. Recovery from Mild Traumatic Brain Injury in Previously Healthy Adults. J Neurotrauma 2016;33:766-76.

54. Williams WH, Potter S, Ryland H. Mild traumatic brain injury and Postconcussion Syndrome: a neuropsychological perspective. $J$ Neurol Neurosurg Psychiatry 2010;81:1116-22.

55. Reuben A, Sampson P, Harris AR, et al. Postconcussion syndrome (PCS) in the emergency department: predicting and pre-empting persistent symptoms following a mild traumatic brain injury. Emerg Med J 2014;31:72-7.

56. Cassidy JD, Cancelliere C, Carroll LJ, et al. Systematic review of selfreported prognosis in adults after mild traumatic brain injury: results of the International Collaboration on Mild Traumatic Brain Injury Prognosis. Arch Phys Med Rehabil 2014;95(3 Suppl):S132-S151.

57. Levin HS, Diaz-Arrastia RR. Diagnosis, prognosis, and clinical management of mild traumatic brain injury. Lancet Neurol 2015;14:506-17.

58. Ingebrigtsen T, Romner B, Kongstad P, et al. Increased serum concentrations of protein S-100 after minor head injury: a biochemical serum marker with prognostic value? J Neurol Neurosurg Psychiatry 1995;59:103-4.

59. Waterloo K, Ingebrigtsen T, Romner B. Neuropsychological function in patients with increased serum levels of protein S-100 after minor head injury. Acta Neurochir 1997;139:26-32.

60. Ingebrigtsen T, Waterloo K, Jacobsen EA, et al. Traumatic brain damage in minor head injury: relation of serum S-100 protein measurements to magnetic resonance imaging and neurobehavioral outcome. Neurosurgery 1999;45:468-76.

61. Ingebrigtsen T, Romner B, Marup-Jensen $\mathrm{S}$, et al. The clinical value of serum S-100 protein measurements in minor head injury: a Scandinavian multicentre study. Brain Inj 2000;14:1047-55.

62. Herrmann M, Curio N, Jost S, et al. Release of biochemical markers of damage to neuronal and glial brain tissue is associated with short and long term neuropsychological outcome after traumatic brain injury. J Neurol Neurosurg Psychiatry 2001;70:95-100.

63. De Kruijk JR, Leffers P, Menheere PP, et al. Prediction of posttraumatic complaints after mild traumatic brain injury: early symptoms and biochemical markers. J Neurol Neurosurg Psychiatry 2002;73:727-32.

64. Townend WJ, Guy MJ, Pani MA, et al. Head injury outcome prediction in the emergency department: a role for protein S-100B? $\mathrm{J}$ Neurol Neurosurg Psychiatry 2002;73:542-6.

65. de Kruijk JR, Leffers P, Menheere PP, et al. Olfactory function after mild traumatic brain injury. Brain Inj 2003;17:73-8.

66. Savola O, Hillbom M. Early predictors of post-concussion symptoms in patients with mild head injury. Eur J Neurol 2003;10:175-81.

67. Stranjalis G, Korfias S, Papapetrou C, et al. Elevated serum S-100B protein as a predictor of failure to short-term return to work or activities after mild head injury. J Neurotrauma 2004;21:1070-5.

68. de Boussard CN, Lundin A, Karlstedt D, et al. S100 and cognitive impairment after mild traumatic brain injury. J Rehabil Med 2005;37:53-7.

69. Stålnacke BM, Björnstig U, Karlsson $\mathrm{K}$, et al. One-year followup of mild traumatic brain injury: post-concussion symptoms, disabilities and life satisfaction in relation to serum levels of S-100B and neurone-specific enolase in acute phase. $J$ Rehabil Med 2005;37:300-5.

70. Stapert S, de Kruijk J, Houx P, et al. S-100B concentration is not related to neurocognitive performance in the first month after mild traumatic brain injury. Eur Neurol 2005;53:22-6.

71. Bazarian JJ, Zemlan FP, Mookerjee S, et al. Serum S-100B and cleaved-tau are poor predictors of long-term outcome after mild traumatic brain injury. Brain Inj 2006;20:759-65.

72. Bazarian JJ, Beck C, Blyth B, et al. Impact of creatine kinase correction on the predictive value of $\mathrm{S}-100 \mathrm{~B}$ after mild traumatic brain injury. Restor Neurol Neurosci 2006;24:163-72.

73. Bulut M, Koksal O, Dogan S, et al. Tau protein as a serum marker of brain damage in mild traumatic brain injury: preliminary results. Adv Ther 2006;23:12-22.

74. Naeimi ZS, Weinhofer A, Sarahrudi K, et al. Predictive value of $\mathrm{S}-100 \mathrm{~B}$ protein and neuron specific-enolase as markers of traumatic brain damage in clinical use. Brain Inj 2006;20:463-8.

75. Sojka P, Stålnacke BM, Björnstig U, et al. One-year follow-up of patients with mild traumatic brain injury: occurrence of posttraumatic stress-related symptoms at follow-up and serum levels of cortisol, S-100B and neuron-specific enolase in acute phase. Brain Inj 2006;20:613-20.

76. Jakola AS, Müller K, Larsen M, et al. Five-year outcome after mild head injury: a prospective controlled study. Acta Neurol Scand 2007;115:398-402.

77. Stålnacke BM, Elgh E, Sojka P. One-year follow-up of mild traumatic brain injury: cognition, disability and life satisfaction of patients seeking consultation. J Rehabil Med 2007;39:405-11.

78. Lima DP, Simão Filho C, Abib SC, et al. Quality of life and neuropsychological changes in mild head trauma. Late analysis and correlation with S100B protein and cranial CT scan performed at hospital admission. Injury 2008;39:604-11.

79. Ma M, Lindsell CJ, Rosenberry CM, et al. Serum cleaved tau does not predict postconcussion syndrome after mild traumatic brain injury. Am J Emerg Med 2008;2668:7636p-768.

80. Schütze M, Kundt G, Buchholz K, et al. [Which factors are predictive for long-term complaints after mild traumatic brain injuries?]. Versicherungsmedizin 2008;60:78-83.

81. Müller K, Ingebrigtsen T, Wilsgaard T, et al. Prediction of time trends in recovery of cognitive function after mild head injury. Neurosurgery 2009;64:698-704.

82. Kleinert K, Schleich F, Biasca N, et al. Is there a Correlation between S100 beta and Post-Concussion Symptoms after Mild Traumatic Brain Injury? Zentbl Chir 2010;135:277-8.

83. Meric E, Gunduz A, Turedi S, et al. The prognostic value of neuron-specific enolase in head trauma patients. J Emerg Med 2010;38:297-301.

84. Topolovec-Vranic J, Pollmann-Mudryj MA, Ouchterlony D, et al. The value of serum biomarkers in prediction models of outcome after mild traumatic brain injury. J Trauma 2011;71:S478-S486.

85. Metting Z, Wilczak N, Rodiger LA, et al. GFAP and S100B in the acute phase of mild traumatic brain injury. Neurology 2012;78:1428-33.

86. Okonkwo DO, Yue JK, Puccio AM, et al. GFAP-BDP as an acute diagnostic marker in traumatic brain injury: results from the prospective transforming research and clinical knowledge in traumatic brain injury study. J Neurotrauma 2013;30:1490-7.

87. Abbasi M, Sajjadi M, Fathi M, et al. Serum S100B Protein as an Outcome Prediction Tool in Emergency Department Patients with Traumatic Brain Injury. Turk J Emerg Med 2014;14:147-52.

88. Diaz-Arrastia R, Wang KK, Papa L, et al. Acute biomarkers of traumatic brain injury: relationship between plasma levels of ubiquitin C-terminal hydrolase-L1 and glial fibrillary acidic protein. $J$ Neurotrauma 2014;31:19-25.

89. Ryb GE, Dischinger PC, Auman KM, et al. S-100 $\beta$ does not predict outcome after mild traumatic brain injury. Brain Inj 2014;28:1430-5.

90. Heidari K, Asadollahi S, Jamshidian M, et al. Prediction of neuropsychological outcome after mild traumatic brain injury using clinical parameters, serum S100B protein and findings on computed tomography. Brain Inj 2015;29:33-40.

91. Dey S, Shukla D. To Study the Acute Phase Serum Biomarkers in Patients with Mild Traumatic Brain Injury (Mtbi) and Correlate with Short Term Cognitive Deficits. J Neurotrauma 2016;33:A8.

92. Yang T, Song J, Bu X, et al. Elevated serum miR-93, miR-191, and miR-499 are noninvasive biomarkers for the presence and progression of traumatic brain injury. J Neurochem 2016;137:122-9. 